\title{
Exploring the Coordinated Management of Meaning of Sex: The Social Construction of Male College Student Logical Forces
}

\author{
Nathan M. Swords', Mark P. Orbe1, Angela Cooke-Jackson'², Amber L. Johnson ${ }^{3}$ \\ ${ }^{1}$ Western Michigan University, Kalamazoo, Michigan, USA \\ ${ }^{2}$ Emerson College, Boston, Massachusetts, USA \\ ${ }^{3}$ Prairie View A \& M University, Prairie View, Texas, USA \\ Email: Nathan.m.swords@wmich.edu, orbe@wmich.edu, Angela Cooke Jackson@emerson.edu, \\ aljohnson@PVAMU.edu
}

Received 23 May 2014; revised 28 June 2014; accepted 12 July 2014

Copyright (C) 2014 by authors and Scientific Research Publishing Inc.

This work is licensed under the Creative Commons Attribution International License (CC BY).

http://creativecommons.org/licenses/by/4.0/

(c) (i) Open Access

\section{Abstract}

This exploratory qualitative research study examined male college students' narratives describing memorable sexual experiences, and how those encounters inform current sexual practices. Drawing from a larger collaborative research project, this study explores the narratives of 130 men who were attending college at one of three diverse US campuses in 2012. Utilizing a coordinated management of meaning theoretical frame we examine how sexual experiences are informed by logical forces of looped narratives that exhibit both charmed and strange loops. Findings demonstrate how men's management of meaning regarding their sexual experiences is informed by larger expectations steeped in rigid masculine values, a major force in socially constructing sexuality.

\section{Keywords}

Men, Sex, Gender, Masculinity, Sexual Experiences, Social Construction

\section{Understanding the Act of Sex}

Significant research regarding sex, gender, and sexual experiences exists across disciplines. An existing theme of existing research has been a focus on exploring first sexual experiences from a gendered perspective. Generally speaking research has found that men, more so than women, expect sexual intercourse earlier in the dating process, and are also more likely to expect sex in the absence of emotional closeness (e.g., Cohen \& Shotland, How to cite this paper: Swords, N. M., Orbe, M. P., Cooke-Jackson, A., \& Johnson, A. L. (2014). Exploring the Coordinated Management of Meaning of Sex: The Social Construction of Male College Student Logical Forces. Creative Education, 5, 1383-1395. http://dx.doi.org/10.4236/ce.2014.515157 
1996). While most women and men report falling in love at least once, men begin dating at earlier ages than young women do (Carpenter, 2005). In a review of early studies, DeLamater (1987) found that males have a more positive emotional reaction to first intercourse than females do, in part because men are ten times more likely than women to have an orgasm during their first experience (see also Sprecher et al., 1995). In comparison to women, men report feeling more pleasure and less guilt (Darling, Davidson \& Passarello, 1992). As illustrated through these studies, the dominant theme of past research investigating gendered perspectives is different, despite the fact that researchers are likely to find as many similarities between women and men's experiences as differences (Canary \& Dindia, 1998; Sprecher et al., 1995).

More recent research has reinforced the differences between women's and men's sexual experiences through studies that have focused on a variety of issues. For instance, Mongeau and colleges (Mongeau, Serewicz, Morr, \& Therrien, 2004; Moor \& Mongeau, 2004) found that men and women have different goals during first dates, with men having higher sexual expectations - especially when alcohol was consumed, something that is typical in sexual situations (see also, Abbey, Zawacki, Buck, \& Clinto, 2001). Sexual intercourse has been established as a means to relieve stress for both women and men (Ein-Dor \& Hirschberger, 2012), however, men's aggressiveness is more dominant than women's, something linked to rigid gender socialization (Mulac, Jansma, \& Linz, 2002) and alcohol consumption (Wilson, Calhoun, \& McNair, 2002). Gender socialization regarding emotional intimacy expectations also has been studied in terms of sexual experiences. This research has explored the psychological meaning of sexual behavior (Peplau, Rubin, \& Hill, 1977), and women and men's emotional support. Disclosing positive feelings for one's partners after sexual activity is positively associated with relational satisfaction, trust, and psychological immediacy (Denes, 2012). Yet, research has demonstrated that these forms of communication are primarily the behaviors that women, and not men, engage in (Burleson, Homstrom, \& Gilstrap, 2005). Yet, through an exploration of gendered communicative styles, Sidelinger, Frisby, and McMullen (2009) found that both feminine women and androgynous men were likely to perform emotionally supportive behaviors.

While a traditional belief is that heterosexual women are more likely to feel a lack of control involving virginity loss than young men, recent studies have suggested that an increasing number of adolescent men experience similar emotions (Wight et al., 2000). Carpenter's (2005) qualitative research project is especially relevant here. Based on in-depth interviews with 61 US Americans from diverse backgrounds, she explored how perceptions of virginity loss were informed by the preconceived values that they brought to the experiences. Specifically, she discovered three metaphors that reflect different perspectives: virginity as a gift, virginity as a stigma, and virginity loss as a rite of passage ${ }^{1}$. According to Carpenter, these metaphors inform larger frameworks through which people understand virginity and influence their sexual practices. For instance, she found that "gifters" were much more likely to practice safer sex compared to individuals who viewed their virginity as a stigma. In terms of sex, most women and men describe their first sexual experiences as satisfying-and even enjoyable (Carpenter, 2005).

As demonstrated within this brief introduction, a significant body of literature on sex, gender, and sexual experiences exists. The vast majority of this research positions women's and men's sexual experiences in contrast to one another, with a particular focus on how experiences relate to relational expectations, emotional intimacy, aggressiveness/coercion, alcohol consumption, and other factors (e.g., Palmer, McMahon, Rounsaville, \& Ball, 2010). Yet, there is little contemporary scholarly research that focuses on how individuals make sense of their sexual experiences in general, and memorable sexual experiences in particular. Sexuality is a social construction (Berger \& Luckmann, 1967) yet researchers have largely failed to study it as such. In an era marked by increased sexual activity, high rates of sexually transmitted infections (STIs) in young adult populations, and billons of dollars of direct costs to treat them (Chesson, Blandford, Gift, Tao, \& Irwin, 2004), explorations on this topic can provide a unique vantage point for communication scholars and practitioners. As documented next, existing literature on the coordinated management of meaning (CMM) provides a valuable conceptual framework to explore how men socially construct meanings of their most memorable sexual experiences. Following an examination on existing literature of CMM, we provide the methodology of the study, followed by an articulation of our findings. We then close with discussion of our findings followed by concluding remarks.

${ }^{1}$ While her focus is on these three dominant metaphors, Carpenter (2005) also identified a small number of individuals who also embrace virginity as worship. 


\section{CMM: Meaning and Action through Storytelling}

Introduced in the mid-1970s (Pearce, 1976), the coordinated management of meaning (CMM) theory is grounded in a basic premise: Communication is the process by which people "cocreate, maintain, and alter social order, personal relationships, and individual identities” (Cronen, Pearce, \& Harris, 1982: p. 64). The theory is conceptualized in broad terms, drawing from many communicative aspects as it explores how reality is constructed in social interaction (Littlejohn, 2009); not surprisingly it has been used in a variety of interpersonal and intercultural contexts (e.g., Bruss et al., 2005; Pearce \& Pearce, 2000). CMM theory contends that people coordinate their lives by managing the ways in which messages have meaning for, and through, larger patterns of meaning (Heath \& Bryant, 2000). Pearce and Cronen (1980) describe communication as "a process in which each person interprets and responds to the acts of another, monitors the sequence, and compares it to his or her desires and expectations” (p. 68). Consequently, a coordinated management of meaning depends on particular interaction rules, the content of messages, and the ways in which various kinds of interaction are structured (Heath \& Bryant, 2000).

According to CMM, people learn behaviors that are appropriate for specific contexts (Pearce, 1976). Specifically, early conceptualizations focused on the interpretative process through which individuals drew from six levels of understanding to create particular meanings (Pearce \& Cronen, 1980; Philipsen, 1995). These six levels are: 1) content (the words used to communicate), 2) speech acts (how we perform the content), 3) contracts (a system of formal and/or informal rules that guide two or more individuals' communication), 4) episodes (communication routines that consist of a describable sequence of speech acts), 5) identity or life scripts (individual's self-perception that shapes, and is shaped by, communication), and 6) cultural archetypes (understandings of speech acts, contracts, episodes, and life scripts that are shared by a particular social group). Collectively, these levels created a hierarchy of meaning whereby understandings at lower levels "were said to be embedded in, and derive their meaning from” (Pearce, 2005: p. 41) Over the past decade, CMM scholars have acknowledged the fluid and dynamic nature of these contexts; accordingly they have adopted models (e.g., LUUUTT model, Daisy Model, SHEDD model) that emphasis the reflexive relationship among contextual levels of understanding (Littlejohn, 2009; Pearce, 2005; Pearce \& Pearce, 2001) that serve as the fundamental logic that people use to frame, or define, experience (Heath \& Bryant, 2000).

CMM is grounded in the premise that communicators engage in two different things in every interaction: "They interpret, or ascribe meaning, and they act-two functions closely tied to one another: Meaning leads to action, and action forms meaning” (italics in original) (Littlejohn, 2009: p. 2000). CMM scholars study how individuals coordinate their meanings and actions over time, often in larger contexts that contain conflicting messages that compete for greater salience (Bruss et al., 2005). According to the theory, this negotiation is best understood through the recognition of two different types of rules: those that are constitutive and regulative (Pearce \& Cronen, 1980). Constitutive rules are guidelines that reveal meaning, they help answer the fundamental question of "What does this mean?” Regulative rules, in contrast, are rules of action, they indicate what actions should be taken in any given communicative context. In short, people interpret messages and know what actions constitute appropriate responses because they can follow rules that guide what they do and say (regulative rules) in the context of how they interpret what transpires (constitutive rules) (Heath \& Bryant, 2000).

Over the course of one's live, rules of meaning and action work to create a logical force that reinforces what is perceived as "logically right" in any given context (Littlejohn, 2009: p. 201). Yet, each individual lives simultaneously in many different social worlds, a reality that means that numerous forms of logic are available to them over the course of their lives (Pearce, 2008). These potentially contradictory sets of regulative and constitutive rules can result in coherence or mystery (Pearce, 2005). When meanings and actions are consistent and reinforcing of one another, a charmed loop is said to exist (coherence). Alternatively, a strange loop is experienced when meanings and actions are contradictory and inconsistent with a person's logical force, something that triggers a quest for new understanding (mystery) (Pearce, 2008). According to CMM, the narratives that an individual shares create a particular social world that includes rules of meaning and action that guide communication with others (Pearce, 2008). Given this, CMM appears as a productive lens through which to explore men's memorable sexual experiences, especially in terms of how individuals negotiate competing messages occurring at different levels of meaning (Bruss et al., 2005). Accordingly, we utilize it as an interpretive lens to gain insight into the following research questions: RQ1: How is meaning situated in male college student's narrations of memorable sexual experiences? and RQ2: What logical forces exist as they create social worlds regarding sex, self, and society? 


\section{Methods}

The data analyzed within this manuscript were collected as a part of a large national study. From April-June, 2012 we conducted a research project focusing on college student sexual experiences and knowledge of sexually transmitted infections. Within this section, we describe the participants, survey, and analytic process of the study.

\subsection{Participants and Procedures}

Participants for this study were recruited from three different college campuses from across the US: 1) a small private urban college located in the Northeast, 2) a large state land grant university located in the upper Midwest, and 3) a mid-sized historically black university in the South. Initially, each of the faculty researchers provided extra credit opportunities to students in their communication classes who volunteered to complete the 10-minute survey on-line. In order to widen and diversify the participant pool, other students across campus beyond this initial scope were also encouraged to participate. Through the process, 476 surveys were collected from the three different campuses: 147 from the Northeast campus, 215 from the Midwest campus, and 114 from the Southern campus. Of the 476 surveys, 130 were completed by men. This smaller data subset, similar in size to other qualitative studies exploring sexual messages (Morgan \& Zurbriggen, 2007), is the focus of our current analysis.

In order to counter existing criticism on the ways that traditional researchers collect and analyze demographic markers such as race, age, and gender (Houston, 2002), demographic information was collected from participants via an open-ended prompt that asked them to provide a self-description of their identity. The approach mirrors the advice of Martin, Krizek, Nakayama and Bradford (1996) who assert that individuals should be asked to provide their own labels, presumably ones that have meaning for them. Because of the lack of consistency in these self-descriptions, reporting participant demographics with any confidence is difficult ${ }^{2}$.

Using an on-line survey, we asked participants a few binary questions (e.g., Have you ever had sex?) and several Likert-style questions that asked about levels of knowledge and awareness of Human Papillomavirus (HPV) and comfort in discussing sex with family members and romantic partners. We also included one openended question that asked participants to provide "a brief but detailed story that describes something from your past-a story, memory, experience, and/or message from another source-that has most impacted your CURRENT SEXUAL PRACTICES”3. This prompt provided a rich source of detailed data concerning a variety of details regarding narratives about memorable sexual messages. This self-report methodological strategy (Lauckner et al., 2012) was consistent with our desire to have participants "narrate their own experiences within these interactions as opposed to asking participants to respond to topics chosen by the researchers” (Morgan \& Zurbriggen, 2007: p. 519). Within this study, participant stories ranged from those that were 1 - 2 sentences long to those that were several paragraphs.

\subsection{Thematic Analytical Process}

In our thematic analysis of narratives, we drew from the work of Owen (1984) and used three criteria (repetition, recurrence, and forcefulness) to assist in the emergence of primary themes (see also Apker, Propp, \& Ford, 2005). Specifically, the thematic analytic process included four steps. First, the 130 responses related to memorable sexual experiences were extracted from the larger data set and organized into one Microsoft Excel sheet. Second, we reviewed this data subset to locate frequent appearances of specific words and phrases (repetition) across participant narratives. Third, we recorded how similar meanings were articulated through various articulations (recurrence) from different participants. Fourth, we also took note of the power behind certain excerpts that were emphasized through different codes (e.g., ALL CAPS), punctuation (!!!! or ???), or format (bold or italics). The initial thematization process generated approximately 10 potential themes. At this juncture, we re-engaged the data using these preliminary themes as conceptualized through a coordinated management of meaning theoretical lens. Through this rigorous process, we were able to facilitate another level of analysis

\footnotetext{
${ }^{2}$ The open-ended self-descriptions that participants provided were coded in terms of different demographic variables. While each category had a significant number of missing data, we do know the following about the sample in terms of: age (29\% under 20; $60 \%$ in their 20 s; 10 unreported), gender (61\% female; $26 \%$ male; $13 \%$ unreported); race/ethnicity (44\% white, $26 \%$ black, $4 \%$ Hispanic, $4 \%$, multiracial; $21 \%$ unreported); and region (45\% Midwest campus, 31\% northeast campus, $24 \%$ southern campus).

${ }^{3} \mathrm{~A}$ copy of the complete survey is available from the first author.
} 
whereby several key over-arching memorable experience-based themes could be identified.

\section{Thematic Results}

Our analysis revealed memorable narratives about sex that largely were limited to descriptions of speech acts and episodes ${ }^{4}$. These memorable narratives cultivated from what the traditional interpretive approach would place at the most basic levels of understanding, in which content descriptions were offered in a certain manner to reflect a particular speech act, or a series of speech acts leading to an episode. Despite their brevity, at the core of these narratives were various issues such as decision making, negative consequences associated with sex, and positive outcomes of practicing safe sex. For instance, one 35-year-old heterosexual male from Michigan explained, "I developed critical thinking skills", which placed decision-making and agency at the foundation of this memorable narrative. One 19-year-old straight white male simply attributed "Watching porn, I guess", to his understanding of sex. Other participants described memorable sexual experiences where meaning was negotiated at the speech act or episode level of understanding. These primarily centered on the negative consequences of obtaining sexually transmitted infections or the result of pregnancy whereas others interpreted messages of the positive results in being sexually active.

One Christian male offered a narrative centered on pregnancy: "Hearing that even with birth control can get a girl pregn[a]nt! So me and my girlfriend now [wear] condoms every time we have sexual intercourse”. Similarly, one 19-year-old white single male expressed the fear of pregnancy in his narrative, "My friends having kids at the age of 16 scared the hell out of me". Whereas narratives similar to these demonstrate speech acts centered on unwanted pregnancies, others revealed obtaining sexually transmitted infections (STI's) at the core of their narratives. "I really don't know anyone that has gotten a STD or HIV but being a responsible person a condom is a must to pro[t]ect from unplanned birth and STDs or HPVs”, described a 20-year-old heterosexual White Catholic male from Michigan.

Other narratives unraveled a more optimistic understanding of sex, describing the positive consequences associated sex education and performing sex. One 19-year-old heterosexual white male from Massachusetts explained, "I just feel like education has made it an easy decision to have safe sex", attributing positive outcomes resulting from sexual education. Similarly one 21-year-old straight White male from Michigan stated, "In elementary school a presentation about teen pregnancies has always made me aware of safe sex". For these individuals, certain speech acts or episodes created a positive understanding of sex and the outcomes of "safe sex". Other participants offered narrative that highlighted the pleasure associated with sex. "I remember the first time I had sex. It was great. I ejaculated within two minutes”, described a 20-year-old Black male. These narratives were primarily descriptive with little context.

The various memorable narratives above depicted meaning situated and limited to the speech act or the episode. Narratives expanded beyond the levels of speech act and episode depicted how levels of understanding can shift and become more elaborate with larger frames of meaning-making. For example, an episode could be best understood in the context of the relationship, or the self could be best understood in the context of the speech act. Relationships between meaning and action rules constitute a reflexive relationship between various contextual frames reflective of more elaborate structures.

\subsection{Reflexive Relationships}

Various narratives constitute a reflexive relationship between meaning and action. A loop metaphor emphasizes the fluidity of contexts and depicts the analytical nature of meaning and action rules. In the traditional hierarchical version of CMM, "the act is understood in terms of the relationship, the relationship in terms of the episode, the episode in terms of the self, and the self in terms of the archetype” (Littlejohn, 2009: p. 200). Utilizing the loop metaphor, however, demonstrates how communicators can shift amongst contexts within given different situations. By providing CMM models that organize each level of understanding for selected narratives, this section will preview how we have provided insight into the meaning making of a few select participant narratives - each of which will demonstrate how meaning was situated in loops of CMM contextual frames.

The value of CMM's loop model is clear in participant narratives that offer descriptions that reflect mean-

${ }^{4}$ The large number of narratives that reflected meaning-making at these basic levels could largely be due to the survey question that was broadly asked and did not require any specific length. Given the length of the survey and that the open-ended question about memorable experiences were one of the last items, it is not surprising that a majority of narratives were fairly brief ( 1 - 2 sentences). 
ing-making across contextual frames. This is evident in all of the memorable sexual narratives that we analyze in this section, including the one featured below. For the participant below, a narrative where identity was understood in the context of the archetype was disclosed. As described by this 21-year-old heterosexual African American male:

After growing up in a catholic grade school from kindergarten to seventh grade I transferred to a public junior high school. After my first [day] I noticed right away the differences between a catholic and public school. One image that changed my sexual life for the rest of my life before it even beg[a]n was seeing a young girl around my age easily six months pregnant and I realized right away I did not want that to be [associated with] me.

For this participant constitutive rules were associated at the archetype level in that the archetype established meaning for how sexual values differ, within his example, from private school to public school (see Figure 1). Transferring from a private school to a public school provided a different culture with different expectations and norms regarding sex. This led to regulative rules that explicitly work to avoid pregnancy while still in school. This narrative is unique in that it does not involve a personal sexual experience, but reflects on an observation of the consequences of someone else's sexual experience.

Several narratives associated within the level of episodes portrayed reflexive relationships among various levels of CMM. While issues of male identity and masculinity were implicit in earlier analyzed narratives, the issue was more explicit in other narratives. This was illustrated by one 21-year-old heterosexual man not in a relationship, who described one episode that was associated with identity or life script:

Yes, I have had sexual encounter before. I will tell the first time I had sex was my freshmen year in high school. I was kind of nervous because I knew it was soon for me to lose my virginity one night after a party I had went to. My girlfriend was a senior in high school obviously with way more experience than me. I went over her cousins place, we kicked it in the living room for a hot second then started kissing. Soon after we took it to the next room. I came prepared that night with like 10 condoms! I have older brothers and they always taught me to always keep condoms with me. As we were kissing she took her pants off and told me to sit down because she was going to get on top of me. Knowing the big ego I had and for my first experience with this whole ordeal, I told her to lay down and I would start everything off. I took my pants off already aroused, put my condom on slightly nervous and started to have sex. That night I felt good about myself lol.

For this participant, constitutive rules were informed by deeper contextual frames but enacted at the episode level in that the episode established meaning for how he should behave (see Figure 2). The participant described how he was not ready for sex, but came prepared to a party with 10 condoms. The episode taking place at his cousin's house after the party created rules of meaning associated with when performing the act of sex should take place. This episode led to regulative rules influenced by his "ego" which coincides with the life script of being a traditional, masculine man. When kissing and told to sit down because she was going to get on top of

$$
\begin{aligned}
& \text { Archetype: Teenage pregnancy/fatherhood is not valued } \\
& \text { Life Script: Don’t have a child at a young age } \\
& \text { Speech Act: Seeing young girl, similar in age, pregnant }
\end{aligned}
$$

Figure 1. CMM Model [Catholic and public school sexual differences].

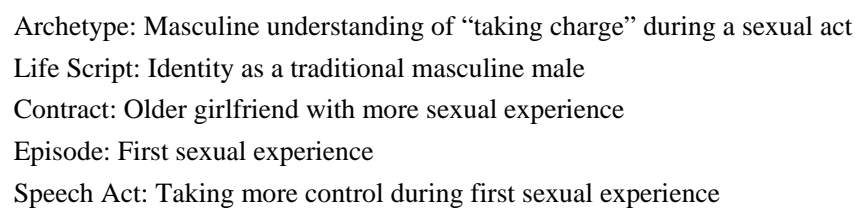

Figure 2. CMM Model [Male ego and first time having sex]. 
him, this male participant described how he told her to lay down as he would "start everything off", describing how his "big ego" influenced his actions during his first experience.

Other narratives demonstrated masculinity as essential to understanding sex. For instance, one twenty-something straight Caucasian Christian male explained:

I'm a male in my twenties. Growing up I was always interested in pornography and would watch it on premiere TV whenever it was on. It introduced me to different things involving sex such as the act and the typical procedure involved with a sexual situation. Once I became sexually active I would refer back to what I had seen growing up and try to get my partners comfortable with what I wanted to do or try. I always wanted to please my partners by giving oral sex and turning them on. Then I would usually go into intercourse. One time I experienced sex with a girl that orgasmed so much that she squirted. I had heard of this before and seen it in porn but had never experienced it personally. I must say, it was very excit[ing] and turned me on greatly! Knowing that I had given my partner such an intense orgasm was such a turn on. From that point on I always strived to give my partners the same experience, not just for their satisfaction but, for mine as well.

This narrative reveals understanding of this interaction was reached through five hierarchical levels of meaning, with rules of meaning and rules of action situated in different levels of understanding, creating a loop of meaning making (see Figure 3).

For this participant constitutive rules were associated at the archetype level in that a cultural artifact-pornography - established meaning for how he should behave. Once sexually active, the participant would refer back to pornography to get new ideas to try with his partner. This lead to regulative rules of control influenced by his masculinity, part of his identity or life script. Pleasing his partners in the way depicted in pornography is described as this participant's sexual objective, and the ability to control his partners' bodily functions served as the ultimate sexual experience for this male participant.

\subsection{Logical Forces of Looped Narratives}

Within this final analysis section we demonstrate the ways in which the participants created cognitive connections between rules of meaning and rules of action, a concept known as a logical force. At the heart of this concept is the idea that individuals create different rules of meaning and action depending on the context of the situation that feel "logically correct". Given that every individual lives within various social spheres, many different "logics" of meaning and action are available. At times individuals can be in limbo over competing rules of meaning and rules of actions.

Logical forces. For the participants of this study, different themes were found at the foundation of their narratives that formed logical forces used to make sense of memorable sexual experiences. These themes include STI protection and pregnancy avoidance, responsibility, and relationship status.

Several participants offered narratives that centered on STI protection and pregnancy avoidance. Some offered how observations of others were used to form logical forces about STI prevention and pregnancy avoidance. This was the case with one 22-year-old white male from Michigan who stated, "I've heard of kids who had unsafe sex and got STDs also pregnant. So [I] always wear a condom! I don’t remember the people's names”. Others described education as the main factor contributing to their logical forces about STI prevention and pregnancy avoidance. As described by one 21-year-old white male from Michigan, his logical force about pregnancy was cultivated during a school assembly, stating that, "In elementary school a presentation about teen pregnancies has always made me aware of safe sex".

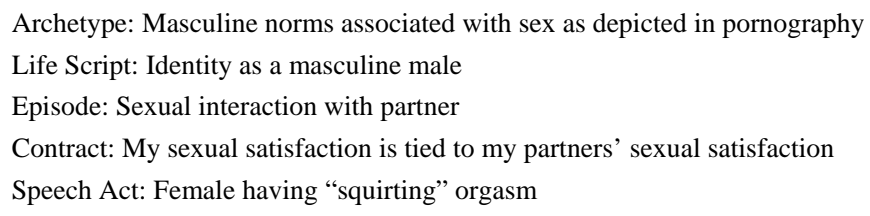

Figure 3. CMM Model [Giving partners intense orgasms is the ultimate satisfaction]. 
Other participants described personal experiences involved with STIs and pregnancy that formed logical forces. One 20-year-old white male provided a narrative about a previous experience with a condom breakingduring sex and how that has impacted his sexual practices, disclosing, "During sexual intercourse when younger the condom broke. I realized how serious the repercussions could be and made sure to be extra careful. Now I am extremely cautious and my partner is now also taking birth control”.

Logical forces centering on the theme of STI prevention and pregnancy avoidance such as above represent a coherent logical force in that the rules of meaning about unsafe sex leading to obtaining STI's and pregnancy prompted consistent rules of action to practice safe sex. A second clear theme that organically developed in our analysis centered on responsibility.

Several participants provided narratives that placed a large importance on responsibility. This second theme differs from the first theme in that these participants provided understandings about sex evolving around being a responsible person, whereas those contributing to the previous theme were specifically concerned with pregnancy and STIs. For example, one 20-year-old male described the teachings he has received from his family about not having sex until marriage:

I come from a Christian family and I have been taught since young to not have sex until marriage. I've been taught that sex leaves a lasting impression on both parties and having sex with multiple partners can destroy one spiritually. I decided to not have sex till marriage because I respect my parent's teachings.

Similarly, another 20-year-old male from Texas attributes his understanding of sex to the sex education that he received from his current partner, saying, "I've learned a lot from my current partner who is very passionate about sex education. It has influenced me to be more responsible and encouraged me to help friends be more responsible".

Narratives such as these focused on the importance of being a responsible person and prompted logical forces between rules of meaning and rules of action. More specifically, these narratives represent contextual forcesways a communicator feels they must act in a given situation (Littlejohn, 2009). Rules of meaning about being sexually responsible through teachings and experiences are consistent with rules of action to practice sexual responsibility.

\subsection{Charmed and Strange Loops}

The loop metaphor provides insight in how understanding can cultivate from the various levels of understanding of CMM. The reflexive relationship between constitutive rules and regulative rules emphasize the systematic nature of shifting contexts. Taking this concept one step further demonstrates the two different types of loops that form to create understanding. As described earlier, a charmed loop is present when meanings and actions a parallel to one another and (re)produce one another. In contrast, a strange loop is present when meanings and actions seemingly contradict one another. In this section, we will provide examples of charmed loops and strange loops to gain a better understanding of how various loop(ed) narratives had either consistent and (re)productive rules of meaning and action or inconsistent and contradictory rules of meaning and action.

Charmed loops. Several participants provided accounts of memorable sexual experiences that demonstrated charmed loops. Themes emerging from charmed loop narratives included various forms of responsibility, pleasure, and masculine values. As one 20-year-old heterosexual male from Houston, TX offered, "I've learned a lot from my current partner who is very passionate about sex education. It has influenced me to be more responsible and encouraged me to help friends be more responsible”. For this narrative, constitutive rules associated in the contract of learning about sex education through his partner has in turn led to regulative rules associated in his life script of identity level of practicing safe sex and helping friends be more responsible with sex.

Other narratives provided more in-depth descriptions that led to the formation of charmed loops. For example, a 20-year-old homosexual white male from Connecticut disclosed how his fear of getting AIDS has led to rules of meaning and rules of action to prevent obtaining AIDS:

Ever since I came out it has been ingrained in my head to be careful about getting AIDS. Because of this, I didn't have my first sexual encounter until I was 17 years old. (Two years after I came out). I also didn't have anal sex until I was 19, because I was so fearful of contracting AIDS. To this day I still remain extremely fearful of AIDS and do not take anal sex lightly. 
For this participant, constitutive rules were interpreted within the speech act of coming out. In addition, being told to take caution regarding AIDS become part of his life script as a young gay man. The messages within these contextual frames led to several regulative rules: wait to have his first sexual encounter, remain extremely fearful of AIDS, and not take anal sex lightly. These rules of action can be best understood in the participant's life script or identity level of understanding. A charmed loop exists between rules of meaning, as a young gay man and rules of action in that he waited to have sex and remains quite cautious when engaging in sex as a way to prevent obtaining AIDS.

Strange loops. In contrast to charmed loops that show consistency between rules of meaning and rules of action, strange loops demonstrate the contradiction and inconsistencies that can exist within meaning-making processes. Although still demonstrating a loop in that they emphasize the fluidity of contexts and depict the analytical nature of meaning and action, these differ from charmed loops in that rules of meaning and rules of action do not align. For example, as one Baptist 21-year-old racially mixed black male described an experience involving a "promiscuous" woman and how it "turned him off":

I had an experience with a girl I was introduced to about 4 years ago. She was very attractive but I was told that she was promiscuous so I went along with it. We were watching a movie at her house and I noticed how often she was itching her private areas. I totally was turned-off but I still got some oral from her. Ever since that experience I became really cautious about who I have sex with, I have to at least have known you for a while before jumping into bed with someone.

Within this experience, the narrative provides rules of meaning and rules of action that seemingly contradict. The constitutive rules established involved being a promiscuous woman itching her private areas; something that was a sexual turnoff. Given this meaning-making, a charmed loop would suppose that regulative rules would facilitate avoidance in terms of any sexual contact. Yet, this male participant explains that he still "got some oral [sex] from her". The rules of action cultivated from the experience involved sexual caution and knowing someone for a while before jumping into bed with them. The inconsistency between constitutive and regulative rules reflects a strange loop; however, it also leaves open the possibility that the participant's regulative rules involve a perception that oral sex is safer than sexual intercourse.

Whereas the previous narrative centered on caution and knowing someone before engaging in sexual intercourse, others were grounded with a need to meet some sort of masculine expectation. For example, a 22-yearold African American male from Texas described a conversation between him and his father about sex which led to him having sex as a way to avoid feeling like "an outcast":

I remember having sex at the age of 17 not because [I] wanted [too] but because of a conversation [I] had with my dad about w[h]ether or not [I] was active or not[.] [A]fter the disscussion [I] went and had sex because [I] didn’t want to feel like an outcast but mostly [I] did it because [I] wanted to [I] was extremely nervous.

As with the previous narrative, this narrative depicts a strange loop between the rules of meaning at the contract level and the rules of action at the speech act level, in that they seemingly contradict. Constitutive rules about being sexual active were understood at the contract level between the man and his father. What it meant to be sexually active or not was negotiated between the man and his father. It appears that what the participant took away from the conversation with his father is that engaging in sex reflects a norm in masculine culture. After the discussion, regulative rules about having sex to not feel like an outcast were then understood. Although he did not have any desires to become sexually active at 17 years old, this participant had sex at age 17 as a way to be accepted into some masculine norms regarding sex and sexual activity.

\section{Discussion}

Our study was designed to explore how male college students socially constructed memorable sexual experiences generally, and how the meanings associated with these experiences influence current sexual practices. Our data was comprised of self-generated narratives, those in which male participants described memorable sexual experiences. Through a coordinated management of meaning theoretical framework, we explored how meaning was constructed in both unidimensional (i.e., via speech acts and episodes) and multidimensional (i.e., reflexive relationships, charmed/strange loops) contextual frames. Utilizing CMM's loop model, we found how men's memorable sexual experiences were implicitly and explicitly informed through larger frames of cultural mascu- 
linity (i.e., through archetypes and life scripts). In addition our thematic analysis of participant narratives reveals logical forces of both charmed and strange loops. Within this context, three themes emerged: Protection against STIs and unwanted pregnancy, responsibility, and relationship status. While we acknowledge the polyvocality of participant narratives (Lyotard, 1984), our findings provide valuable insight into the complexity of how men socially construct meaning around sexual experiences.

A significant outcome of our study lies within the ways it demonstrates the ways that masculine archetypes influence and inform the social construction of male sexual experiences. Through several CMM loop analyses, narratives illustrated how their decisions about sex, as well as their role during sexual encounters, reflect negotiations of larger values regarding masculinity. We focused on one memorable experience narrative, however, future studies might find greater insight through analyses of multiple narratives describing memorable experiences. As such, future research can add considerable depth to the existing literature by examining how current behaviors are informed by clusters of memorable narratives that are oftentimes complementary and oppositional. In addition to CMM, scholars interested in this line of research might draw from the concept of sensemaking as articulated by Weick (1995). Grounded in both individual and social activities, sensemaking "involves turning circumstances into a situation that is comprehended explicitly in words and that serves as a springboard into action” (Weick, Sutcliffe, \& Obstfeld, 2005: p. 409). Sensemaking occurs within a larger societal frame, and incorporating gender role theories—like those established by Eagly (1987) and Bem (1981)—would prove invaluable to understanding how individuals negotiate societal expectations and personal preferences (McCabe et al., 2010). Specific research projects that explore how individuals make sense of multiple, sometimes competing, memorable experiences about sex appear as potentially insightful and heuristically rich. Future research is needed to further explore the salient factors, in addition to sex and gender, that inform memorable experiences regarding sexual intimacy 5 .

Our study also lays the foundation for future research that reflects both theoretical, methodological, and practical value. A major contribution of our exploratory study of male sexual experiences to existing literature is the productive ways in which we investigated the narratives of memorable experiences given the powerful ways in which they serve as a template for understanding human life (Browning, 2009). We have used CMM to focus on how men make meaning of their own sexual experiences, in the context of complimentary and competing contexts of understanding (Bruss et al., 2005). However, CMM is quick to point out that "communicators must manage their own meanings and actions, while responding to the meanings and actions of others" (Littlejohn, 2009: p. 200). Our study focuses on men's narratives of memorable sexual experiences, and provides valuable insight into the perspectives that are part of their social worlds (Pearce \& Pearce, 2001). While important in this regard, the research is limiting in that it does not incorporate relational contexts through which meaning is given to sexual experiences. Future research might consider collecting narratives from relational partners to explore how the negotiation of meaning exists within social constructions that include self, other, and relationship. This approach is consistent with a social construction approach given that people jointly construct their understandings of the world (Berger \& Luckmann, 1967).

Using a CMM loop model (Pearce, 2005) provided an opportunity to focus in on the functions that narratives play in the creation of meaning and action. In this conceptualization, CMM acknowledges how the stories that are told construct a world of meanings and actions; yet it also recognizes how narratives can never tell the entire story at any given time (Littlejohn, 2009). Utilizing CMM as a practical theory (Pearce \& Pearce, 2000), then, can involve "an attempt to change the mode of storytelling to one that has more opportunities for good things to happen” (Pearce, 2005: p. 48). We believe, as Littlejohn (2009) does, that "patterns of communication can be changed and expanded and coordination achieved by telling and different stories” (p. 203). In the context of men's memorable sexual narratives, we wonder what might this look like-especially if practitioners could create contexts where men make meaning of their sexual experiences with others who are negotiating masculine values in ways that resist traditional conceptualizations (Anderson, 2010; Burleson, Holmstrom, \& Gilstrap, 2005). What stories might they tell in an emotionally supportive environment? How might the nature and meanings of these stories shift, and in turn alter their social constructions of sex, gender, and sexuality?

In regards to methodology, our study highlights the productive ways in which on-line surveys can engage a large, diverse participant pool and collect anonymous, confidential data on a sensitive (if not taboo) topic such

\footnotetext{
${ }^{5}$ Within this particular analysis, we have focused exclusively on sex and gender within male narratives. However, in other analyses, we utilize the large data set to engage the intersectionality of sexual memorable experiences based on gender, race, sexual orientation, spirituality, and regional location.
} 
as sex. While much of the data was frank, honest, and uncompromising, collecting via an open-ended survey question also was limiting in that we did not have any opportunities to directly engage with participants, something that hindered our ability to ask follow-up clarifying questions ${ }^{6}$. Future research on sexual memorable experiences, like that which we've outlined in this discussion section, would be wise to facilitate data collection strategies that allow for extended exchanges that can provide greater depth and contextualization. Conducting such research on-line (e.g., via personal or group chats) exists as a distinct possibility (see, for example, Grabner-Kanter \& Kaluscha, 2003). Engaging participants through communicative channels that foster trust and confidentiality is crucial to maximizing the depth and richness of data.

\section{Conclusion}

We conclude with some brief comments regarding the practical implications of this line of research. CMM is "a valuable resource for understanding, describing, and facilitating the development of new forms of communication called for by the challenges of contemporary society” (Pearce, 2005: p. 36). As a theory with practical applications, CMM analyses demonstrate how narratives can represent a crucial tool to assist in understanding how individuals make sense of their sexual experiences. This understanding — of both self and others' experiencesis a salient factor in creating a healthy attitude toward human sexuality, something advocated by the World Health Organization:

Sexual health is a state of physical, emotional, mental and social well-being related to sexuality; it is not merely the absence of disease, dysfunction or infirmity. Sexual health requires a positive and respectful approach to sexuality and sexual relationships, as well as the possibility of having pleasurable and safe sexual experiences, free of coercion, discrimination and violence (World Health Organizations, 2002, as cited in Carpenter, 2005: p. 194).

Promoting a healthy attitude toward human sexuality must be a core objective within any contemporary sex education efforts. While some sex education curriculum has proven success in delaying teen sex, a recent study reported that outdated curriculum-including antiquated stereotypical thinking in terms of gender-are hindering their ultimate success (Wong, 2012). This shortcoming is reflective of younger generations negotiation, or blatant rejection, of traditional masculine and feminine roles.

Within this research endeavor we sought out the narrations of college males to better understand how meanings of sex are socially constructed. Using coordinated management of meaning (CMM) as a theoretical lens we discovered multiple themes centered on rigid masculine values that participants referenced to construct meanings of sex and gender. Understanding how individuals in the $21^{\text {st }}$ century make meaning of their own sexuality must acknowledge shifting attitudes regarding gender identity and expression. Without this type of recognition, efforts to promote a healthy attitude toward sex will continue to fall short.

\section{References}

Abbey, A., Zawacki, T., Buck, P. O., \& Clinton, A. M. (2001). Alcohol and Sexual Assault. Alcohol Research \& Health, 25, 43-51.

Anderson, E. (2010). At Least with Cheating There Is an Attempt at Monogamy: Cheating and Monogamism among Undergraduate Heterosexual Men. Journal of Social and Personal Relationships, 27, 851-872. http://dx.doi.org/10.1177/0265407510373908

Apker, J., Propp, K. M., \& Ford, W. S. Z. (2005). Negotiating Status and Dentist Pensions in Healthcare Team Interactions: An Exploration of Nurse Rule Dialectics. Journal of Applied Communication Research, 33, 92-115. http://dx.doi.org/10.1080/00909880500044620

Bem, S. L. (1981). Gender Schema Theory: A Cognitive Account of Sex Typing. Psychological Review, 88, 354-364. http://dx.doi.org/10.1037/0033-295X.88.4.354

Berger, P., \& Luckmann, T. (1967). The Social Construction of Reality: A Treatise in the Sociology of Knowledge. Garden City, NY: Doubleday.

Browning, L. (2009). Narrative and Narratology. In S. W. Littlejohn, \& K. A. Foss (Eds.), Encyclopedia of Communication

\footnotetext{
${ }^{6}$ In fact, some narratives were so short that it proved difficult to get a sense of what made the particular experience so memorable for the participant. Having opportunities to further engage participants for greater explanation and clarification would be extremely valuable in further understanding their experience.
} 
Theory (pp. 673-677). Thousand Oaks, CA: Sage. http://dx.doi.org/10.4135/9781412959384.n253

Bruss, M. B., Morris, J. R., Dannison, L. L., Orbe, M., Quitugua, J. A., \& Palacios, R. T. (2005). Food, Culture and Family: Exploring the Coordinated Management of Meaning Regarding Childhood Obesity. Health Communication, 18, 155-175. http://dx.doi.org/10.1207/s15327027hc1802_4

Burleson, B. R., Holmstrom, A. J., \& Gilchrist, C. M. (2005). “Guys Can’t Say That to Guys”: Four Experiments Assessing the Normative Motivation Account for Deficiencies in the Emotional Support Provided by Men. Communication Monographs, 72, 468-501. http://dx.doi.org/10.1080/03637750500322636

Canary, D., \& Dindia, K. (Eds.) (1998). Sex Differences and Similarities in Communication: Critical Essays and Empirical Investigations of Sex and Gender in Interaction. Mahwah, NJ: Lawrence Erlbaum.

Carpenter, L. M. (2005). Virginity Lost: An Intimate Portrait of First Sexual Experiences. New York: New York University Press.

Chesson, H. W., Blandford, J. M., Gift, T. L., Tao, G., \& Irwin, K. L. (2004). The Estimated Direct Medical Cost of Sexually Transmitted Diseases among American Youth, 2000. Perspectives on Sexual and Reproductive Health, 36, 11-19. http://dx.doi.org/10.1363/3601104

Cohen, L. L., \& Shotland, R. L. (1996). Timing of the First Sexual Intercourse in Relationship: Expectations, Experiences and Perceptions of Others. Journal of Sex Research, 33, 291-299. http://dx.doi.org/10.1080/00224499609551846

Cronen, V. E., Pearce, W. B., \& Harris, L. M. (1982). The Coordinated Management of Meaning: A Theory of Communication. In F. E. X. Dance (Ed.), Human Communication Theory: Comparative Essays (pp. 61-89). New York: Harper \& Row.

Darling, C. A., Davidson, K., \& Passarello, L. C. (1992). The Mystique of First Intercourse among College Youth: The Role of Partners, Contraceptive Practices, and Psychological Reactions. Journal of Youth and Adolescence, 21, 97-117. http://dx.doi.org/10.1007/BF01536984

DeLamater, J. (1987). Gender Differences in Sexual Scenarios. In K. Kelley (Ed.), Females, Males, and Sexuality (pp. 127-140). Albany: State University of New York Press.

Denes, A. (2012). Pillow Talk: Exploring Disclosures after Sexual Activity. Western Journal of Communication, 76, 91-108. http://dx.doi.org/10.1080/10570314.2011.651253

Eagly, A. H. (1987). Sex-Differences in Social Behaviors: A Social-Role Interpretation. Hillsdale, NJ: Lawrence Erlbaum.

Ein-Dor, T., \& Hirschberger, G. (2012). Sexual Healing: Daily Dairy Evidence that Sex Relieves Stress for Men and Women in Satisfying Relationships. Journal of Social and Personal Relationships, 29, 126-139. http://dx.doi.org/10.1177/0265407511431185

Grabner-Kanter, S., \& Kaluscha, E. A. (2003). Empirical Research in On-Line Trust: A Review and Critical Assessment. International Journal of Human-Computer Studies, 58, 783-812.

Heath, R. L., \& Bryant, J. (2000). Human Communication Theory and Research: Concepts, Contexts, and Challenges.

Houston, M. (2002). Seeking Difference: African Americans in Interpersonal Communication Research, 1975-2000. Howard Journal of Communications, 13, 25-41. http://dx.doi.org/10.1080/106461702753555021

Lauckner, C., Smith, S., Kotowski, M., Nazione, S., Stohl, C., Prestin, A., So, J., \& Nabi, R. (2012). An Initial Investigation into Naturally Occurring Loss- and Gain-Framed Memorable Breast Cancer Messages. Communication Quarterly, 60, 1-16. http://dx.doi.org/10.1080/01463373.2012.642269

Littlejohn, S. W. (2009). Coordinated Management of Meaning. In S. W. Littlejohn, \& K. A. Foss (Eds.), Encyclopedia of Communication Theory (pp. 200-203). Thousand Oaks, CA: Sage. http://dx.doi.org/10.4135/9781412959384.n76

Lyotard, J. F. (1984). The Post Modern Condition: A Report on Knowledge. G. Bennington, \& B. Massumi, Trans., Minneapolis, MN: University of Minnesota Press.

Martin, J. N., Krizek, R. L., Nakayama, T. K., \& Bradford, L. (1996). Exploring Whiteness: A Study of Self-Labels for White Americans. Communication Quarterly, 44, 125-144. http://dx.doi.org/10.1080/01463379609370006

McCabe, J., Tanner, A. E., \& Heiman, J. R. (2010). The Impact of Gender Expectations on Meanings of Sex and Sexuality: Results from a Cognitive Interview Study. Sex Roles, 62, 252-263. http://dx.doi.org/10.1007/s11199-009-9723-4

Mongeau, P. A., Serewicz, M. C. M., \& Therrien, L. F. (2004). Goals for Cross-Sex First Dates: Identification, Measurement, and the Influence of Contextual Factors. Communication Monographs, 71, 121-147. http://dx.doi.org/10.1080/0363775042331302514

Moor, M. C., \& Mongeau, P. A. (2004). First-Date Expectations: The Impact of Sex of Initiator, Alcohol Consumption, and Relationship Type. Communication Research, 31, 3-35. http://dx.doi.org/10.1177/0093650203260202

Morgan, E. M., \& Zurbriggen, E. L. (2007). Wanting Sex and Wanting to Wait: Young Adults’ Accounts of Sexual Messages from First Significant Dating Partners. Feminism \& Psychology, 17, 515-541. 
http://dx.doi.org/10.1177/0959353507083102

Mulac, A., Jansma, L. L., \& Linz, D. G. (2002). Men’s Behavior toward Women after Viewing Sexually-Explicit Films: Degradation Makes a Difference. Communication Monographs, 69, 311-328. http://dx.doi.org/10.1080/03637750216544

Owen, W. (1984). Interpretive Themes in Relational Communication. Quarterly Journal of Speech, 70, $274-287$. http://dx.doi.org/10.1080/00335638409383697

Palmer, R. S., McMahon, T. J., Rounsaville, B. J., \& Ball, S. A. (2010). Coercive Sexual Experiences, Protective Behavioral Strategies, Alcohol Expectancies and Consumption among Male and Female College Students. Journal of Interpersonal Violence, 25, 1563-1578. http://dx.doi.org/10.1177/0886260509354581

Pearce, K. A., \& Pearce, W. B. (2001). The Public Dialogue Consortium’s School-Wide Dialogue Process: A Communication Approach to Develop Citizenship Skills and Enhance School Climate. Communication Theory, 11, 105-123. http://dx.doi.org/10.1111/j.1468-2885.2001.tb00235.x

Pearce, W. B. (1976). The Coordinated Management of Meaning: A Rules-Based Theory of Interpersonal Communication. In G. Miller (Ed.), Explorations in Interpersonal Communication (pp. 17-36). Beverly Hills, CA: Sage.

Pearce, W. B. (2005). The Coordinated Management of Meaning (CMM). In W. B. Gudykunst (Ed.), Theorizing about Intercultural Communication (pp. 35-54). Thousand Oaks, CA: Sage.

Pearce, W. B. (2008). Making Social Worlds. Boston, MA: Blackwell.

Pearce, W. B., \& Cronen, V. E. (1980). Communication, Action, and Meaning: The Creation of Social Realities. New York: Praeger.

Pearce, W. B., \& Pearce, K. A. (2000). Extending the Theory of the Coordinated Management of Meaning (CMM) through a Community Dialogue Process. Communication Theory, 10, 405-423. http://dx.doi.org/10.1111/j.1468-2885.2000.tb00200.x

Peplau, L. A., Rubin, Z., \& Hill, C. T. (1977). Sexual Intimacy in Dating Relationships. Journal of Social Issues, 33, 86-109. http://dx.doi.org/10.1111/j.1540-4560.1977.tb02007.x

Sidelinger, R. J., Frisby, B. N., \& McMullen, A. L. (2009). The Decision to Forgive: Sex, Gender, and the Likelihood to Forgive Partner Transgressions. Communication Studies, 60, 164-179. http://dx.doi.org/10.1080/10510970902834890

Sprecher, S., Barbee, A., \& Schwartz, P. (1995). Was It Good for You, Too? Gender Differences in First Sexual Intercourse Experiences. Journal of Sex Research, 32, 3-15. http://dx.doi.org/10.1080/00224499509551769

Weick, K. (1995). Sensemaking in Organizations. Thousand Oaks, CA: Sage Publications.

Weick, K., Sutcliffe, K. M., \& Obstfeld, D. (2005). Organizing and the Process of Sensemaking. Organization Science, 16, 409-421. http://dx.doi.org/10.1287/orsc.1050.0133

Wight, D., Henderson, M., Raab, G., Abraham, C., Buston, K., Scott, S., \& Hart, G. (2000). Extent of Regretted Sexual Intercourse among Young Teenagers in Scotland: A Cross-Sectional Survey. British Medical Journal, 320, $1243-1244$. http://dx.doi.org/10.1136/bmj.320.7244.1243

Wilson, A. E., Calhoun, K. S., \& McNair, L. D. (2002). Alcohol Consumption and Expectancies among Sexually Coercive College Men. Journal of Interpersonal Violence, 17, 1145-1159. http://dx.doi.org/10.1177/088626002237399

Wong, K. (2012). Students Dangerously Misled by Outdated Sex-Ed Courses, Report Reveals. http://living.msn.com/love-relationships/the-heart-beat-blog-post?post=1cb00424-5a98-4856-9060-d8e5e045c96d\&-nwpt $=1$ 
Scientific Research Publishing (SCIRP) is one of the largest Open Access journal publishers. It is currently publishing more than 200 open access, online, peer-reviewed journals covering a wide range of academic disciplines. SCIRP serves the worldwide academic communities and contributes to the progress and application of science with its publication.

Other selected journals from SCIRP are listed as below. Submit your manuscript to us via either submit@scirp.org or Online Submission Portal.
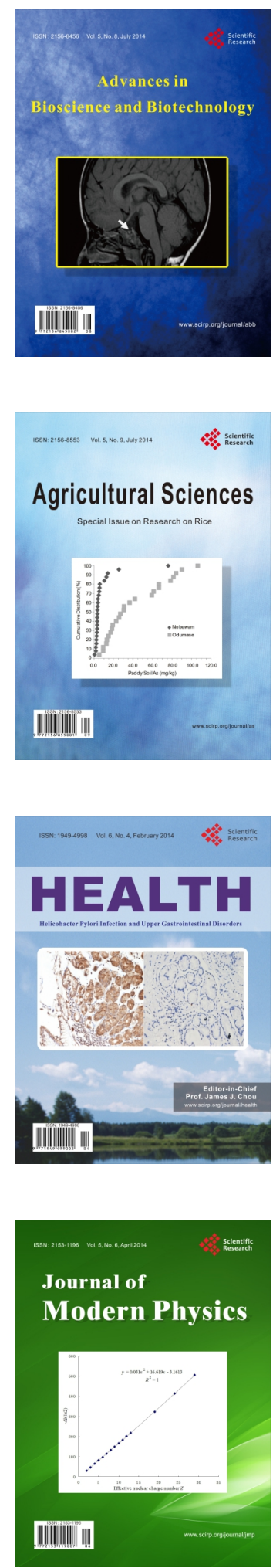
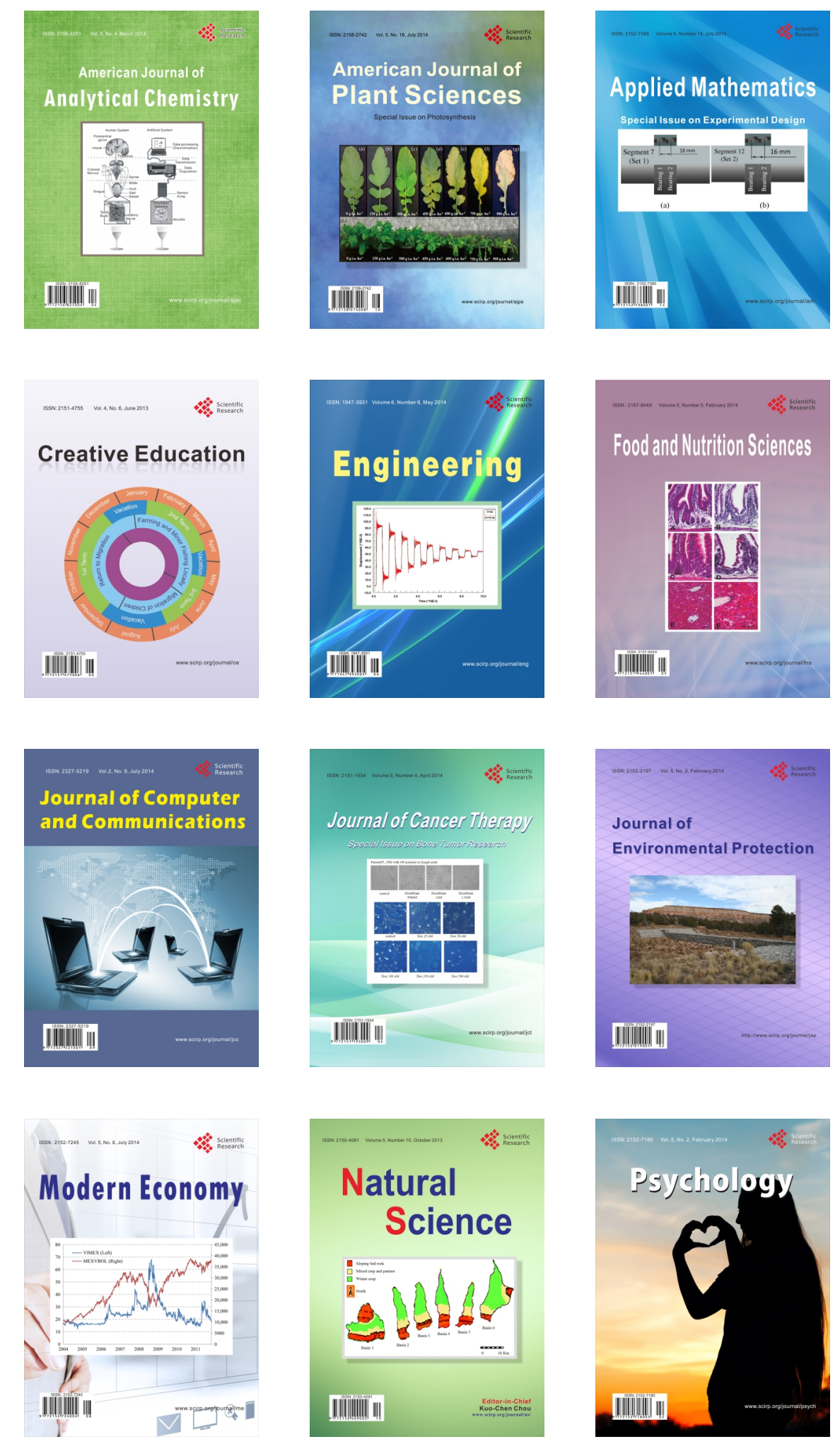